\title{
Electrochemical Interaction Between Free Radicals and Lappaconitines
}

\author{
Xiuli Niu ${ }^{1}$, Yingqiang Zhang ${ }^{2}$, Gaofeng Shi ${ }^{2, *}$ Guoying Wang ${ }^{2, * *}$ \\ ${ }^{1}$ Gansu Province Food Inspection Institute, Lanzhou, P. R. China \\ ${ }^{2}$ School of Petrochemical Engineering, Lanzhou University of Technology, Lanzhou, 730050, China \\ *E-mail: gaofengshi_lzh@163.com ${ }^{* *}$ E-mail: wangguoying@lut.cn
}

doi: $10.20964 / 2018.11 .02$

Received: 3 April 2018 / Accepted: 2 July 2018 / Published: 1 October 2018

\begin{abstract}
We used electrochemical analysis methods to study how the aconitum alkaloids lappaconitine and its salts (HBr-lappaconitine, HCl-lappaconitine) scavenge free radicals (superoxide anion radical, 2,2diphenyl-l-picrylhydrazyl, hydroxyl radical and lipid peroxy radical) on a multiwall carbon nanotubemodified glassy carbon electrode. The experimental results showed that lappaconitine, $\mathrm{HBr}$ lappaconitine and $\mathrm{HCl}$-lappaconitine scavenge free radicals. Lappaconitine's free-radical scavenging capacity decreased in the order 2,2-diphenyl-1-picrylhydrazyl > hydroxyl radical > superoxide anion radical > lipid peroxy radical. HBr-lappaconitine's free-radical scavenging capacity decreased in the order 2,2-diphenyl-1-picrylhydrazyl > lipid peroxy radical > hydroxyl radical > superoxide anion radical. HCl-lappaconitine's free-radical scavenging capacity decreased in the order hydroxyl radical > 2,2-diphenyl-1-picrylhydrazyl > superoxide anion radical > lipid peroxy radical. Scavenging ability toward 2,2-diphenyl-1-picrylhydrazyl and lipid peroxy radical decreased in the order $\mathrm{HBr}$ lappaconitine > lappaconitine > HCl-lappaconitine. Scavenging ability toward superoxide anion radical and hydroxyl radical decreased in the order lappaconitine > HBr-lappaconitine > HCl-lappaconitine. The results show that the lappaconitine and its salts can be developed as natural antioxidants because of their free-radical scavenging activities.
\end{abstract}

Keywords: Lappaconitine; Electrochemical characterization; Free radical; Antioxidant capacity

\section{FULL TEXT}

(C) 2018 The Authors. Published by ESG (www.electrochemsci.org). This article is an open access article distributed under the terms and conditions of the Creative Commons Attribution license (http://creativecommons.org/licenses/by/4.0/). 